any, reach threshold at $1.8 \mathrm{mM} \mathrm{Ca}^{2+}$. However, they can all be driven to threshold by tetanic stimulation. This may indeed represent a form of competitive interaction between axons of the same nerve. In fact, it is apparently a more uniformly strong form of synaptic repression than we observe between pairs of foreign nerves.

ALAN D. GRINNELL

Department of Biology and

Brain Research Institute,

University of California, Los Angeles

Los Angeles, California 90024

MARY B. RHEUBEN

Department of Biology,

Pennsylvania State University,

University Park, Pennsylvania 16802

MICHAEL S. LETINSKY

Department of Physiology and

Brain Research Institute,

University of California, Los Angeles

Los Angeles, California 90024

1. Luff, A. R. \& Proske, U. J. Physiol., Lond. 258, 673-684 (1976).

\section{X-ray dose fractionation and oncogenic transformations in cultured mouse embryo cells}

I AGREE with the main conclusion of Miller and $\mathrm{Hall}^{1}$ that it is unwise to use data from experiments using single high doses of a carcinogen to estimate the likely effects of chronic low doses. However, in presenting their data they have used an inappropriate statistical technique which has in some cases considerably overestimated the accuracy of the observations which they present to support this conclusion. For example, for cells irradiated once with $50 \mathrm{rad}$ they estimate the standard error of their observed transformation frequency per million surviving cells to be \pm 4 , whereas in fact, it should be about \pm 44 and possibly appreciably more.

The discrepancy arises as follows. They reported two experiments at $50 \mathrm{rad}$. In the first they observed a transformation frequency per million survivors of 137 (based on discovering a total of just four transformed colonies among some tens of thousands of survivors) and in the second they observed a transformation frequency of 130 (based on discovering just five colonies). Their final estimate of the transformation frequency per million survivors is $133 \pm 4,133$ being the simple average of 137 and 130 and \pm 4 being based only on the coincidental similarity of the observed values 137 and 130 , and taking no account of how these values arose. However, it is appropriate when estimating standard errors from such data to bear in mind that only nine colonies have been discovered altogether, and as the $95 \%$ confidence interval corresponding to an observed count of nine is 4-17, the $95 \%$ confidence interval for the transformation frequency per million survivors should be at least as wide as 60-250 (and possibly appreciably wider, if other sources of error could be allowed for). If correct confidence intervals had been plotted in their Fig. 2 the surprising lack of any trend whatever in the split-dose data between 20 and 300 rad would be less definitely anomalous. (In addition, a minor improvement in data management would have been to use, instead of the average of the observed rates, the sum of the numbers of transformed colonies divided by the sum of the numbers of survivors.)

Department of the Regius,

RICHARD PETO

Professor of Medicine,

Radcliffe Infirmary,

Oxford, UK

1. Miller, R. \& Hall, E. J. Nature 272, 58-60 (1978).

MILlER AND HALL REPLY-Peto's comment on our paper ${ }^{1}$ is fair and justified. The statistical analysis of data from transformation experiments of mammoth proportions, which yield only a half dozen or so transformed colonies from tens of thousands of irradiated cells, is a difficult problem. In retrospect, we should have quoted the standard errors based on Poisson statistics of the number of colonies observed, as well as the standard error calculated from the repeat experiments. In essence, Peto's point is that the closeness with which the absolute level of the transformation rate repeated between experiments was fortuitous, and on statistical grounds he is correct.

The main purpose of the experiments described, however, was to show that split doses produce more transformations than a single exposure of the same total dose. This conclusion still holds however the data are analysed. In experiments of this kind, the greatest reliance can be placed on comparisons within a given experiment, and in every case a significantly greater number of transformed colonies arise from split than from single doses. To establish the shape of the dose-response curve, much larger experiments would be necessary in which, preferably, several doses are used within the same experiment. This is not feasible for logistical reasons.

ERIC J. HALL RICHARD MILLER

Department of Radiology,

Radiological Research Laboratories, College of Physicians and Surgeons, Columbia University,

New York, New York 10032

1. Miller, R. \& Hall, E. J. Nature 272, 58-60 (1978).

\section{Age of earliest mid-latitude glaciation}

SHACKLETON AND OPDYKE ${ }^{1}$ conclude, from oxygen isotopic analyses of core V28-179, that no large ice sheets accumulated in the Northern Hemisphere until about 3.2 Myr ago, shortly before the Mammoth event of the Gauss normal epoch. The core extends down into the upper Gilbert reversed epoch, and the bottom is estimated to be $3.6-3.5 \mathrm{Myr}$ old; they conclude that from then until 3.2 Myr ago, Earth had a stable interglacial' or 'preglacial' climate. However, this is not true for the Southern Hemisphere. In South America the first recognised glaciation of Pleistocene severity occurred about $3.5 \mathrm{Myr}$ ago, after the Cochiti event of the Gilbert reversed epoch; $50 \mathrm{~km}$ east of the Andean mountain front at about latitude $49^{\circ} \mathrm{S}$, glacial till is interbedded with reverselymagnetised lava flows $3.55 \pm 0.07 \mathrm{Myr}$ old (above) and $3.48 \pm 0.09 \mathrm{Myr}$ old (below) (dated by the whole rock $\mathrm{K} \mathrm{Ar}$ method $)^{2,3}$. This terrestrial evidence is consistent with some faunal analyses of Gilbert and Gauss-age cores obtained between latitudes $55^{\circ} \mathrm{S}$ and $63^{\circ} \mathrm{S}$ in the Southern Ocean, which show severe climatic conditions in the late Gilbert after the Cochiti event ${ }^{4-6}$; sea ice may then have extended $1^{\circ}$ to $1.5^{\circ}$ north of its present position ${ }^{6,10,11}$. If ice age cold prevailed in middle latitudes of the Southern Hemisphere 0.3 Myr before the initial formation of the Northern Hemisphere ice sheets, this would present an intriguing palaeoclimatic problem. It would suggest that these ice sheets could not form until after some further environmental change in the Northern Hemisphere: for example, uplift of the Labrador-Ungava Peninsula ${ }^{7}$, or final closure of the Central American seaway $^{8.9}$. More core analyses are evidently needed for a definitive reconstruction of global climatic and glacial events during the middle Pliocene.

\section{J. H. MERCER}

Institute of Polar Studies,

The Ohio State University,

Columbus, Ohio 43210

\footnotetext{
1. Shackleton, N. J. \& Opdyke, N. D. Nature 270, 216-219 (1977).

2. Mercer, J. H., Fleck, R. J., Mankinen, E. A. \& Sander, W in Quaternary Studies (eds Suggate, R. P. \& Cresswell, M. M.) 223-230 (Royal Society of New Zealand, Wellington, 1975).

3. Mercer, J. H. Quat. Res. 6, 125-166 (1976).

4. Keany, J. Mar. Micropalaeont. 3, 35-49 (1978)

4. Keany, J. Mar. Micropalaeont. 3, 35-49 (1978).
5. Ciesielski, P. F. and Weaver, F. M. Geology 2, 511-515

(1974).
6. Weaver, F. M. thesis, Florida State Univ. (1976).

7. Cooke, H. C. Royal Society of Canada Transactions, ser. 3 23, section 4, 91-120 (1929).

8. Crowell, J. C. \& Frakes, L. A. Am. J. Sci. 268, 193-224 (1970).

9. Edgar, N. T. et al. Init. Rep. DSDP 15, 1077-1111 (1973).

10. Luyendyk, B. P., Forsyth, D. \& Phillips, J. D. Geol. Soc. Am. Bull. 83, 2649-2664 (1972).

11. Berggren W. A. \& Hollister, C. D. Tectonophysics 38 , 11-48 (1977)
} 